Article

\title{
A Database of Force-Field Parameters, Dynamics, and Properties of Antimicrobial Compounds
}

\author{
Giuliano Malloci, Attilio Vittorio Vargiu *, Giovanni Serra, Andrea Bosin, Paolo Ruggerone \\ and Matteo Ceccarelli
}

Dipartimento di Fisica, Università degli studi di Cagliari, Cittadella Universitaria, I-09042 Monserrato (Cagliari), Italy; E-Mails: giuliano.malloci@dsf.unica.it (G.M.); gserra@dsf.unica.it (G.S.); andrea.bosin@dsf.unica.it (A.B.); paolo.ruggerone@dsf.unica.it (P.R.); matteo.ceccarelli@dsf.unica.it (M.C.)

* Author to whom correspondence should be addressed; E-Mail: vargiu@dsf.unica.it; Tel.: +39-070-675-4911; Fax: +39-070-675-3191.

Academic Editor: Peter Ertl

Received: 11 June 2015 / Accepted: 28 July 2015 / Published: 3 August 2015

\begin{abstract}
We present an on-line database of all-atom force-field parameters and molecular properties of compounds with antimicrobial activity (mostly antibiotics and some beta-lactamase inhibitors). For each compound, we provide the General Amber Force Field parameters for the major species at physiological $\mathrm{pH}$, together with an analysis of properties of interest as extracted from $\mu$ s-long molecular dynamics simulations in explicit water solution. The properties include number and population of structural clusters, molecular flexibility, hydrophobic and hydrophilic molecular surfaces, the statistics of intraand inter-molecular H-bonds, as well as structural and dynamical properties of solvent molecules within first and second solvation shells. In addition, the database contains several key molecular parameters, such as energy of the frontier molecular orbitals, vibrational properties, rotational constants, atomic partial charges and electric dipole moment, computed by Density Functional Theory. The present database (to our knowledge the first extensive one including dynamical properties) is part of a wider project aiming to build-up a database containing structural, physico-chemical and dynamical properties of medicinal compounds using different force-field parameters with increasing level of complexity and reliability. The database is freely accessible at http://www.dsf.unica.it/translocation/db/.
\end{abstract}


Keywords: antimicrobial compounds; molecular databases; all-atom force fields; molecular dynamics simulations

\section{Introduction}

The study of dynamical interactions between drugs and their biological targets (such as nucleic acids and proteins) is of paramount importance in medicinal chemistry and related fields (see e.g., [1,2]). Among the many tools, numerical computations including molecular dynamics (MD) simulations have gained an ever increasing role in addressing key structural, dynamical, thermodynamic and kinetic features at a molecular level of detail [3-11]. Furthermore, thanks also to the steep increase in computational power (e.g., the recent porting on GPUs allowed the all-atom simulations of porins embedded and solvated in membrane beyond the $\mu$ s timescale [12]), MD simulations are no longer a mere complement to experiments, but truly inspire new research lines and experimental work [5,6,13-16].

Dynamical interactions can be described in MD simulations by means of different models (see e.g., [17]): from full-quantum descriptions further approximations lead to mixed classical-quantum (QM/MM), all-atom, mixed molecular mechanics/coarse-grained (MM/CG) and coarse-grained (CG) models to represent "atomic" interactions.

In particular, MD simulations based on all-atom empirical "force-fields", nowadays routinely performed in the microsecond timescale, have been proven to yield structural, dynamical, thermodynamical, and kinetic information with good accuracy [5,14,15]. Irrespective of the physical model used to describe interatomic forces, the key ingredient of empirical MD simulations are the parameters entering terms of the force-field, which are usually fitted to reference experimental or theoretical data [18]. The use of the latter scheme, facilitated by the introduction of the Amber 95 force field [19], allowed to improve considerably the range of application/accuracy of empirical simulations. The possibility to perform high quality ab-initio calculations has indeed allowed the fitting to any property, including those not or partly accessible through experiments. An example in this direction was the use of DFT to calculate all vibrational frequencies and related eigenvectors of a chromophore [20], that once reproduced by the empirical parameters has opened the way to investigate more precisely the elecronic-vibrational coupling in photosynthesis [21]. The force-fields widely used today in biomolecular simulations have reached a very good level of description of structural and dynamical properties of common macromolecules such as proteins [22], nucleic acids [23], and membranes [24], although corrections and improvements have been recently proposed [25]. However, the parametrization of generic molecules (drugs, dyes, etc.) remains often a non-trivial task [26], despite the efforts in developing (semi-)automatic parametrization tools. Among the widely used public databases and tools are the R.E.DD.B. [27,28] and the AMBER parameter [29] databases. Obtaining reliable force-fields for general molecules requires the combination of several tools and expertise, from chemical characterization [30] to classical [31] and/or quantum calculations [32] at different levels, as well as chemical, physical, and biological intuition. 
Recently, as part of the activity of the TRANSLOCATION consortium within the Innovative Medicines Initiative antimicrobial resistance programme, New Drugs for Bad Bugs [33], we have undertaken a long-term project with the goal of building a large database of antimicrobial compounds (and medicinal compounds in general) containing, for each molecule, all-atom parameters compatible with different existing biological force fields, as well as microsecond-long dynamics and physico-chemical descriptors in different physiological conditions. Thus, using several established computational tools we have started a systematic investigation on antimicrobial compounds of different classes. Besides the specific application to the study of bacterial resistance mediated by the membrane barrier [34,35], our database contains molecular information possibly useful in different contexts such as, for example, receptor-ligand molecular docking and indirect assessment of role of flexibility in the interpretation of experimental results (see Section 4).

This work constitutes the first step of the aforementioned wider project: we report a homogenous database of the computed molecular properties for a sample of 40 different antimicrobial compounds ranging in size from $\sim 20$ to $\sim 80$ atoms (see Table A1 in the Appendix). For each compound, we provide the General Amber Force Field parameters [36] for the major species at physiological $\mathrm{pH}$, together with an analysis of properties of general interest, including number and population of relevant structural clusters, molecular flexibility, hydrophobic and hydrophilic molecular surfaces, as well as the statistics of intra- and inter-molecular H-bonds, hydration shells structure and dynamics, etc., as extracted from $\mu$ s-long molecular dynamics simulations in explicit water solution. In addition, the database includes several key molecular parameters, such as energy of the frontier molecular orbitals, normal modes of vibration, rotational constants, atomic partial charges and electric dipole moment, computed by Density Functional Theory. This database is freely accessible on-line at the address http://www.dsf.unica.it/translocation/db/ and is suitable for further inclusion of new data.

\section{Computational Methods}

For each compound we obtained the 3D structure data file (SDF format) from the Pubchem database [37]. We then used the ChemAxon's Marvin suite of programs [30] to calculate the dominant tautomer distribution and thus find the protonation/charge state most populated at physiological $\mathrm{pH}=7.4$. We used the same package to obtain other general properties of interest, such as the net charge dependence on $\mathrm{pH}$, the isoelectric point $\mathrm{pI}$, the Van der Waals volume, the number of rotatable bonds, and the number of H-bond donors/acceptors.

\subsection{QM Calculations}

The structure of the major species determined in the above step has been subsequently used as an input to quantum-chemical calculations at the Density Functional Theory level [38]. For this part of the work we used the Gaussian09 package [32]. In particular, we employed the widely used hybrid B3LYP functional, a combination of exact (Hartree-Fock) exchange with local and gradient-corrected exchange and correlation terms [39,40], in conjunction with the split-valence 6-31G ${ }^{\star \star}$ Gaussian basis-set [41]. The combination B3LYP/6-31G ${ }^{\star \star}$ represents a good compromise between accuracy and computational cost $[42,43]$. In all cases considered we disabled the use of molecular symmetry (Symmetry=None), 
adopted very restrictive convergence criteria for both self-consistent-field iterations $\left(10^{-8} \mathrm{Ha}\right.$, SCF (Conver=8)) and geometry optimizations (Opt (VeryTight)), and used a pruned $(99,590)$ grid (Int=UltraFine) for numerical integration. For each compound we optimized the ground-state structure employing the Polarizable Continuum Model [44] as to mimic the effect of water solvent $(\mathrm{SCRF}=(\mathrm{PCM}$, Solvent $=$ Water $))$ particularly to avoid formation of strong intra-molecular H-bonds. To confirm the geometry obtained to be a global minimum on the potential energy surface we performed full vibrational analyses obtaining real frequencies in all cases. We processed the output of Gaussian09 with GaussSum [45] and Gabedit [46] to extract orbital data, and vibrational spectra, respectively.

On the optimized geometry we then performed B3LYP/6-31G ${ }^{\star \star}$ single-point energy calculations in vacuum to generate the atomic partial charges fitting the molecular electrostatic potential. Under the constraint of reproducing the overall electric dipole moment of the molecule, we used both Merz-Kollman [47] ( $\mathrm{P} O \mathrm{p}=\mathrm{MK})$ and CHELPG [48] ( $\mathrm{P} \mathrm{p}=\mathrm{CHel} \mathrm{pG})$ schemes to construct a grid of points around the molecule. Atomic partial charges were then generated through the two-step restrained electrostatic potential (RESP) method [49] implemented in the Antechamber package [50]. Following the same procedure we additionally extracted the standard $\mathrm{HF} / 6-31 \mathrm{G}^{*}$ point charges, which are fully compatible with the charge derivation protocol within AMBER [49]. The derivation of consistent charges is hardly a straightforward task for which specifically devoted tools and databases have been developed, such as the R.E.DD.B. database to give an example [27,28]. Finally, for the B3LYP/6-31G ${ }^{\star \star}$ optimized geometry, we computed $\log \mathrm{P}$ values using the XLOGP3 program [51], and polar/non-polar molecular surfaces with the PLATINUM web interface [52].

\subsection{Simulations}

We performed all-atom molecular dynamics simulations in the presence of explicit water solution $(0.1 \mathrm{M} \mathrm{KCl})$ using the Amber14 package [31]. Model systems were prepared with the program tleap of AmberTools14 [31] adopting the TIP3P model of water [53] and the monovalent ion parameters appropriate for this choice [54]. For the antibiotics we used the General AMBER Force Field (GAFF) parameters [36]. For all systems under investigation we used the following procedure. First, geometry optimization was conducted with a two-step protocol: (i) 10,000 cycles (1000 of steepest descent plus 9000 of conjugate gradient) with harmonic restraint $\mathrm{k}=10 \mathrm{kcal} \cdot \mathrm{mol}^{-1} \cdot \AA^{-2}$ on each heavy atom of the solute and (ii) 10,000 conjugate gradient cycles without restraints. Next, an heating to $400 \mathrm{~K}$ followed by a cooling to $310 \mathrm{~K}$ were accomplished via NVT MD runs for $2 \mathrm{~ns}$ and $10 \mathrm{~ns}$, respectively. As a last step preceding the productive dynamics, NPT MD was conducted for 1 ns to relax the simulation box. Finally, $1 \mu$ s-long MD simulations were performed under the NPT ensemble. Pressure and temperature were regulated at $1 \mathrm{Atm}$ and $310 \mathrm{~K}$ using the isotropic Berendsen barostat [55] and the Langevin thermostat [56], respectively. Electrostatic interactions were evaluated using the particle mesh Ewald scheme with a cutoff of $9.0 \AA$ for the short-range evaluation in direct space. The same cutoff was used for Lennard-Jones interactions (with a continuum model correction for energy and pressure) [31]. 


\subsection{Post-Processing of the MD Trajectories}

From the all-atom MD simulations we obtained structural and dynamical features of the compounds investigated by means of the PTRAJ and CPPTRAJ programs [57]. In detail, we extracted first and second water shells using a lower (upper) cutoff of 3.4 (5.0) $\AA$. For the analysis of intra- and inter-molecular $\mathrm{H}$-bonds we adopted angle and distance cutoffs of $135^{\circ}$ (donor-hydrogen-acceptor angle) and $3.5 \AA$ (donor-acceptor), respectively [58-62]. The number and population of structural clusters were determined using a hierarchical agglomerative algorithm [63]. To evaluate atomic root mean square fluctuations we used the utility g_rms f of GROMACS [64]. During the MD runs we also monitored three morphology descriptors related to the gyration tensor, i.e., asphericity, acylindricity, and kappa2, as implemented in the PLUMED plugin [65]. Asphericity and acylindricity give a measure of the deviation of the mass distribution from spherical and cylindrical symmetry, respectively; the relative shape anisotropy kappa2 is limited between 0 and 1 and reflects both symmetry and dimensionality [66]. The dynamical evolution of the minimal projection area has been determined with the combined use of Open Babel [67] and ChemAxon's Calculator Plugin [30]. Molecular graphics have been generated by using the PYMOL [68] and VMD [69] packages. The overall computational protocol adopted is schematically depicted in Figure 1.

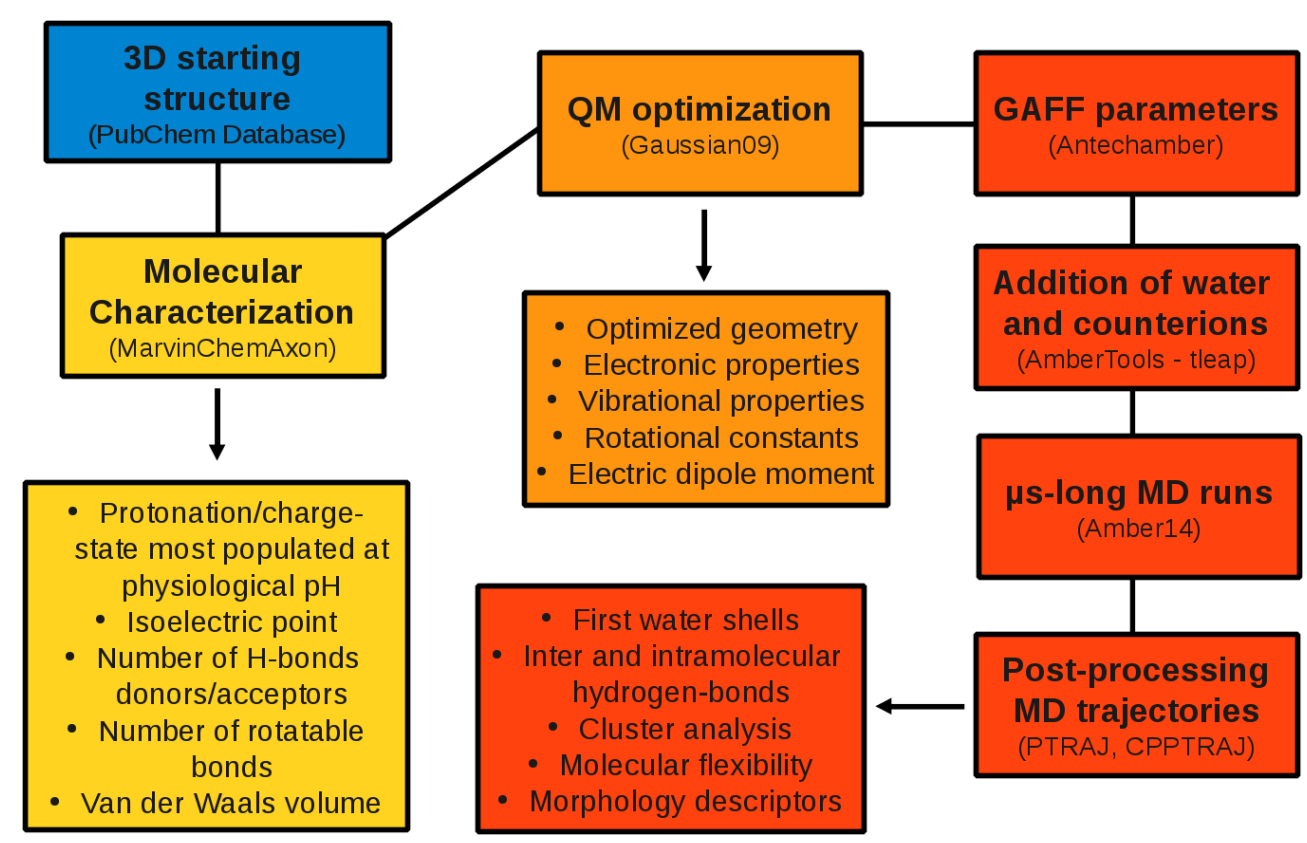

Figure 1. Computational protocol adopted (See Section 2 for a description).

\section{Results}

\subsection{General Structure of the Database}

The total of 40 species presently included in the database, ranging in size from clavulanic acid $(22$ atoms, molecular weight $=198.1528 \mathrm{Da})$ to tigecycline $(82$ atoms, molecular weight $=586.6566 \mathrm{Da})$, covers eight different classes of antibiotics and related compounds, namely: carbapenems, cephalosporins, 
monocyclic beta-lactams, oxazolidinones, penicillines, quinolones, tetracyclines, and beta-lactamase inhibitors. Antimicrobial compounds of these classes are the most widely used against infections caused by Gram-negative bacteria, such as Escherichia coli, Pseudomonas aeruginosa, Salmonella aenterica and Klebsiella pneumoniae. The complete set of compounds included in the current version of the database, together with some of their general properties are listed in Table A1 of the Appendix. Most of the parameters we provide play a key role in determining the translocation of small molecules, such as antibacterials, through bacterial porins [70-72], as well as their extrusion by efflux pumps [73-75], which are among the key topics of the New Drugs for Bad Bugs programme [33].

The main-page http://www.dsf.unica.it/translocation/db/ contains the full list of compounds ordered, within each class, by increasing molecular weight (see Figure 2A). As shown in the left side of the picture, a direct link to the official web-page of all of the computer packages and tools employed is also given. A separate page can then be accessed for each given molecule (Figure 2B). The latter includes a 2D representation of the selected molecule as well as the corresponding QM-optimized 3D structure that can be interactively manipulated by activating a JSmol script [76]. The General AMBER Force Field (GAFF) parameters files (.prep and . frcmod formats [36]) generated with the AmberTools package [31] can be downloaded within each compound's page (Figure 2C). We provide three sets of atomic point-charges computed in vacuum: the standard HF/6-31G(d) (molecule_mk_hf.prep) and the B3LYP/6-31G(d,p) charges fitting the molecular electrostatic potential using the CHELPG (molecule_chelpg.prep) and Merz-Kollman (molecule_mk.prep) schemes (see Section 2).

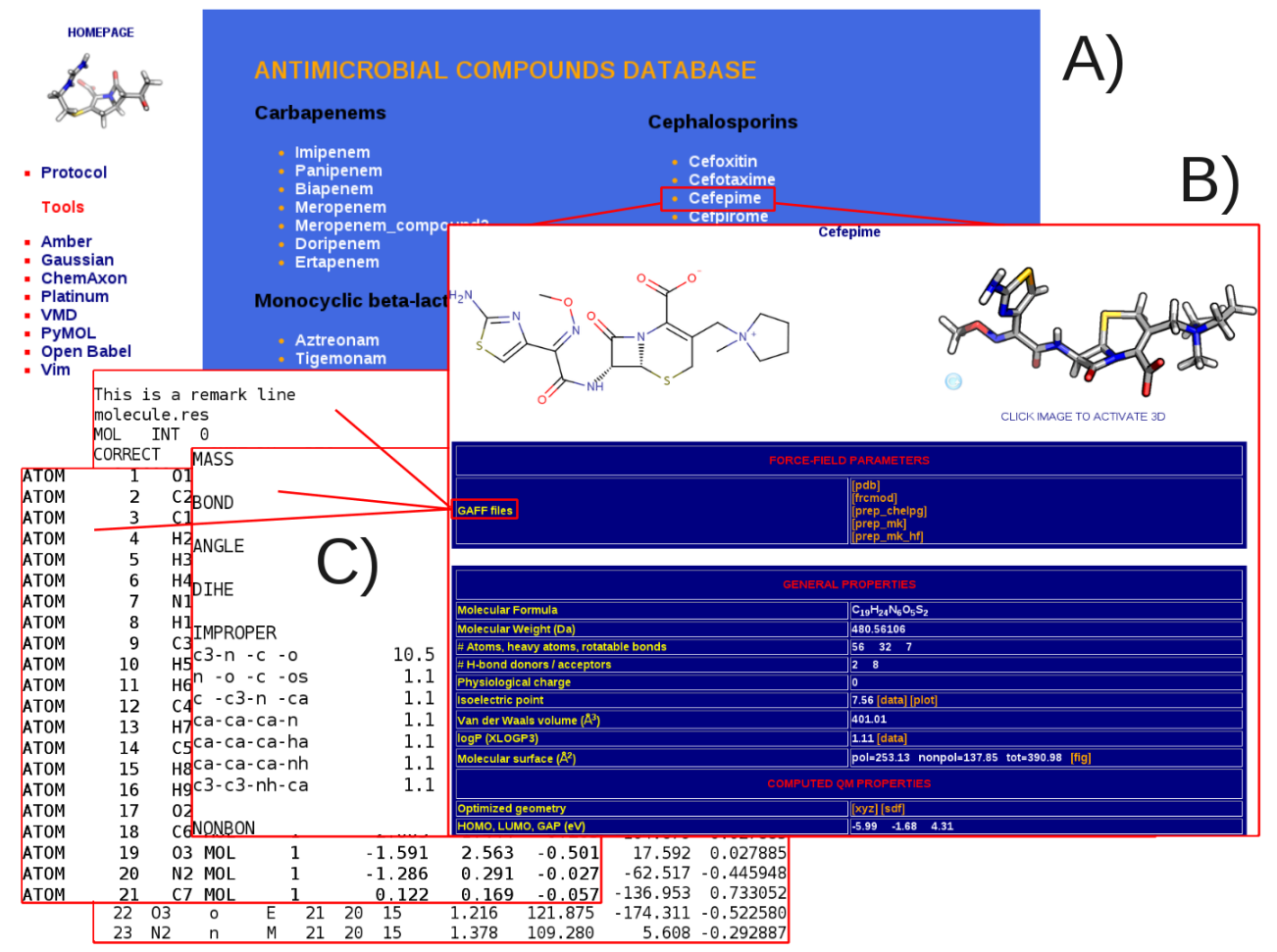

Figure 2. Snapshots of the main page of the database (A); an individual page (B); and the General Amber Force Field parameters files downloadable for each compound $(\mathbf{C})$.

A separate table reports general properties as well as molecular descriptors extracted from both quantum-mechanics and molecular-dynamics simulations. As shown in Figure 3, among general 
properties we report molecular formula, molecular weight, number of atoms and rotatable bonds, number of H-bond donors/acceptors, physiological charge, Van der Waals volume, isoelectric point $\mathrm{pI}$ and $\mathrm{pH}$-dependent net charge of the molecule. For the quantum-optimized structure we provide also $\log \mathrm{P}$ values [51], and polar/non-polar molecular surfaces [52]. In the quantum-mechanical section (Figure 4) the ground-state optimized geometry is available in both plain . xyz and MDL .sdf formats. For the above molecular structure we report: energy of the highest-occupied molecular orbital (HOMO) and lowest-unoccupied molecular orbital (LUMO), HOMO-LUMO gap, rotational constants, and electric dipole moment computed in vacuum and implicit water. The whole set of orbital data and the corresponding plots (density of electronic states, virtual and occupied levels) extracted with GaussSum [45] (Figure 4B), as well as the list of harmonic vibrational frequencies and integrated absorption coefficients with the corresponding IR absorption spectrum obtained with gabedit [46] are also provided (Figure 4C). A graphical representation of the spatial orientation of the electric dipole is additionally given (Figure 4D).

Figure 5 offers a visual representation of some of the molecular descriptors extracted from the MD simulations. The complete set includes: number of solvent molecules within first and second solvation shells, the statistics of intra- and inter-molecular H-bonds, number and population of structural clusters, molecular flexibility expressed in terms of root mean square fluctuations, as well as dynamical behavior of asphericity, acylindricity, and kappa2.

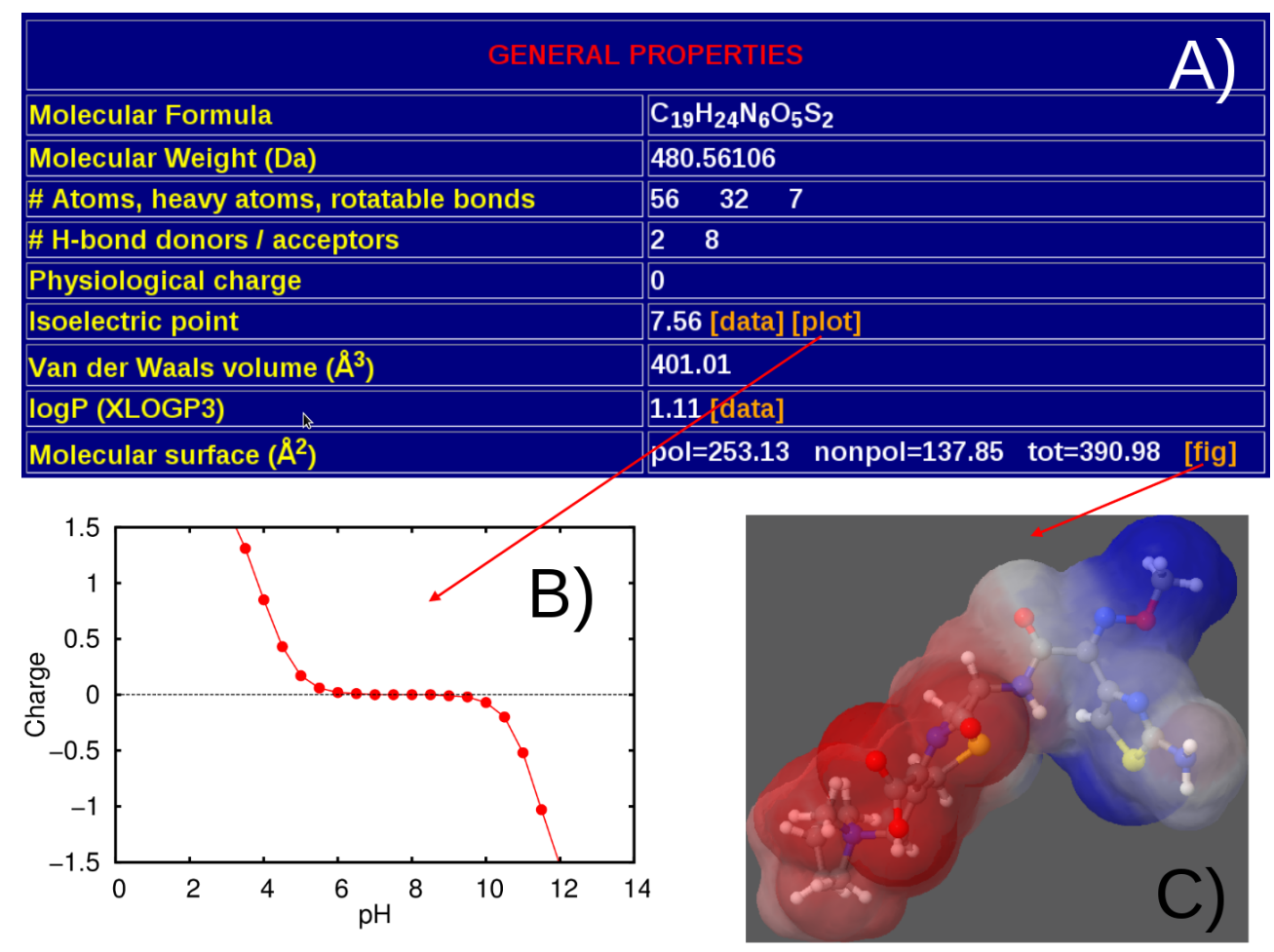

Figure 3. Snapshots of the general properties available for each compound (A); the molecular net charge dependence on $\mathrm{pH}$ computed with MarvinSketch [30] (B); and the polar/non-polar (red-white-blue color scale) molecular surfaces evaluated with the PLATINUM server [52] (C). 


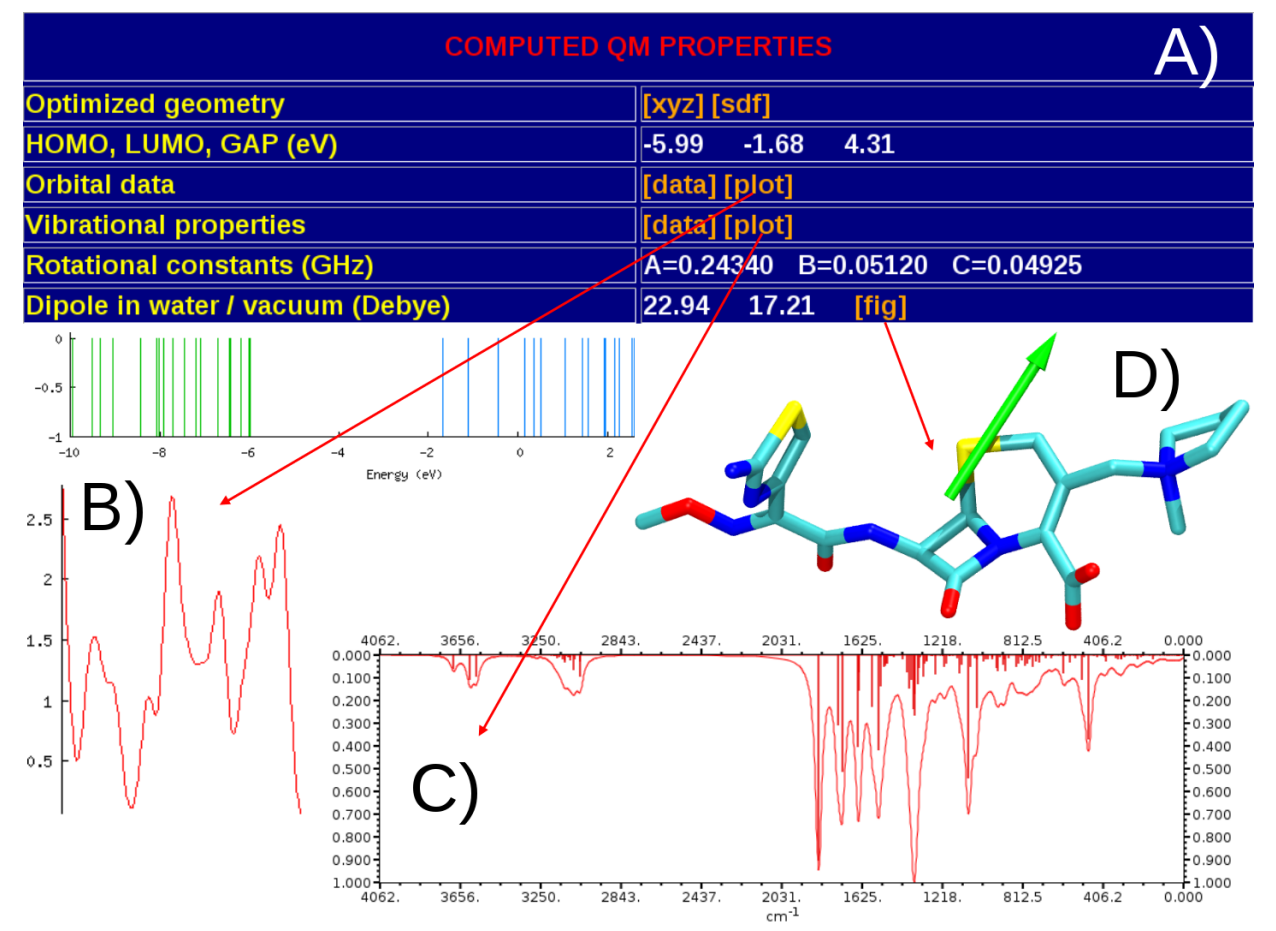

Figure 4. Snapshots of the list of molecular properties exctracted from QM calculations (A); the electronic (B); and vibrational spectra (C); and the visual representation of the electric dipole moment (D).

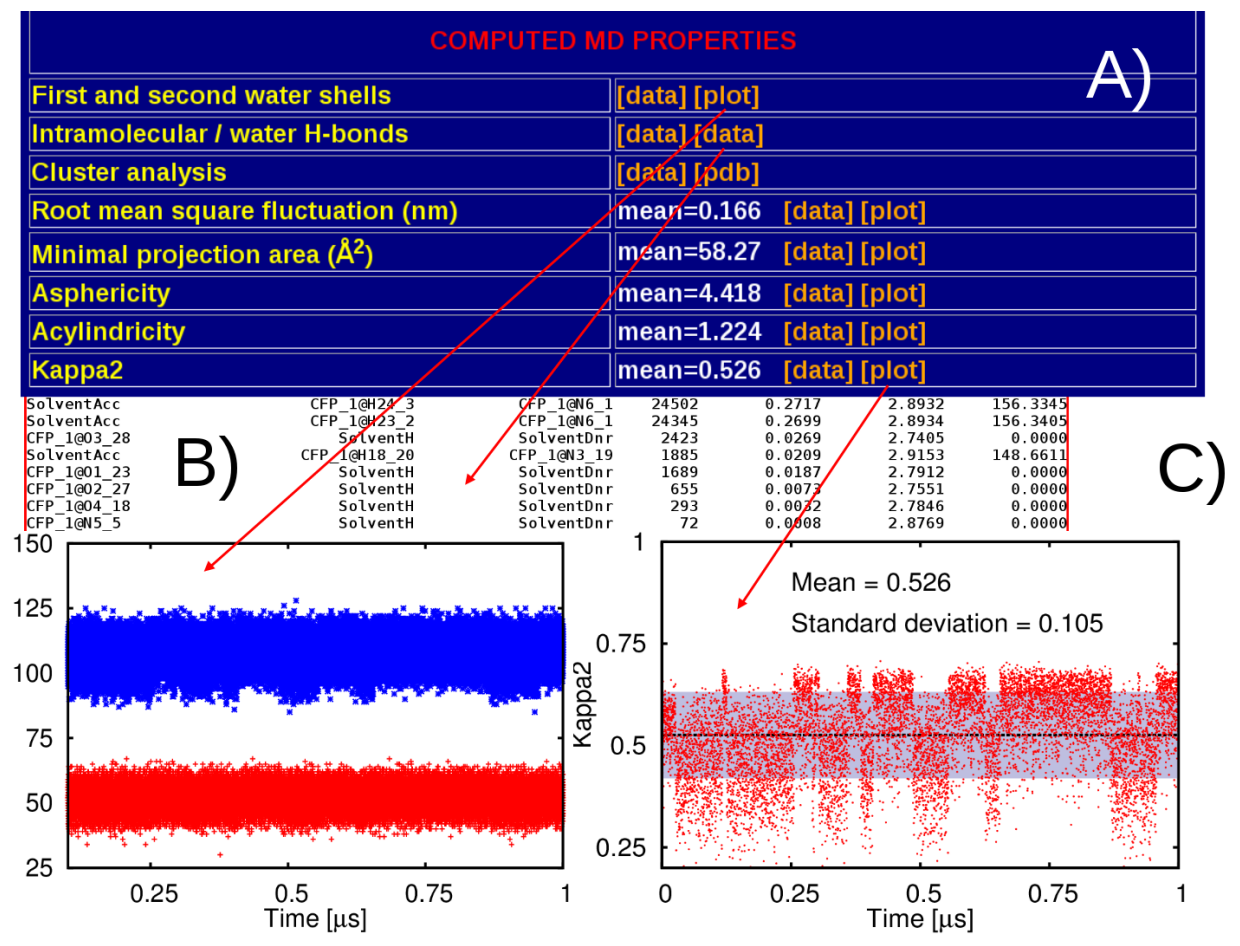

Figure 5. Snapshots of the some of the molecular properties exctracted from MD trajectories (A); as an example we report first and second water shells and statistics of solute-solvent H-bonds (B), and the dynamical behaviour of the relative shape anisotropy $(\mathbf{C})$. 


\section{Discussion}

Among the antimicrobial compounds included in this release of the database, those for which all of the above data are simultaneously available from experiments is relatively small. Thanks to the ever increasing computational power available, the use of modeling tools represents the best alternative to obtain homogenously-derived physico-chemical descriptor of molecules, and can be furthermore useful as a guide for future experimental work. There are many Internet resources reporting relevant data for a large number of compounds of medicinal interest (PubChem, ChemSpider, DrugBank, Chemicalize, etc.). However, to the best of our knowledge, the present database is the first extensive one reporting structural, physico-chemical, and especially dynamical properties obtained combining different computational tools (in particular $\mu$ s-long long MD simulations). There are basically three different levels of active use of our data. First of all the obvious stand-alone use of the tabulated static and dynamical properties of selected compounds. Second, the availability of the (at the moment only) GAFF parameters for the major microspecies at physiological $\mathrm{pH}$, makes possible to straightforwardly perform MD simulations with ready-to-use input files. Finally, the knowledge of the dynamical behavior of a large number of molecular descriptors extracted from $\mu$ s-long MD runs allows performing statistical analyses that go beyond the availability of one static value. This piece of information can find a plethora of possible applications, for example in the field of molecular docking, just to mention one. Most of the available docking programs take into account ligand flexibility only in terms of rotatable bonds of one given input structure (see e.g., rDock [77] and AutoDock Vina [78]) or in terms of small deformations around an equilibrium conformation, derived e.g., by applying normal modes or related analyses [79]. However, as largely demonstrated particularly in the case of protein-protein interactions [80-87], the availability of different conformations sampled by the ligand during MD simulations can be crucial also (perhaps mostly) in protein-ligand docking [73,86,88-90], considerably improving the protocol and making possible to find otherwise unaccessible binding conformations. This is particularly true in the context of conformational selection theory [7], where conformations having low probability in the absence of receptor are populated by the onset of ligand-protein interactions.

The knowledge of the values distribution for specific molecular descriptors can be also useful in the study of structure-dynamics-activity relationships by means of specific molecular descriptors. For instance, the minimal projection area (MPA) has been recently used [91] in the context of bacterial resistance mediated by Resistance-Nodulation Division (RND) multidrug efflux transporters [92-97], to identify a correlation between reduced efflux activity by mutants of the transporter AcrB and the size of substrates. Table 1 reports the MPAs computed for the smallest and largest compound within each of the eight classes considered in the present work. The table reports the dynamical values extracted from the MD trajectories and compares them with the static ones publicly available from Chemicalize [98]. As shown in Table 1 the value reported in Chemicalize fall in the Mean \pm Stdev range in almost all cases considered; a relevant exception is represented by ertapenem for which Chemicalize predicts the corresponding MPA to be larger than about $26 \%$ with respect to our mean value. Taking into account the minimum and maximum values and the corresponding range of variability, the distribution of the computed MPAs displays large deviations (from $\sim 10 \%$ up to $\sim 40 \%$ ) around the mean value. Thus, our 
data can be used to take into account the dynamical nature of interacting partners when studying ligand transport processes, as well as any interaction dynamics between antibiotics and their targets.

Table 1. Comparison between minimal projection areas taken from Chemicalize [98] and the average values and range of variability extracted from MD runs for selected compounds.

\begin{tabular}{|c|c|c|c|}
\hline \multirow{2}{*}{ Compound } & \multicolumn{3}{|c|}{ Minimal Projection Area $\left(\AA^{2}\right)$} \\
\hline & Chemicalize & Mean \pm Stdev & Min, Max (Delta) \\
\hline \multicolumn{4}{|c|}{ Carbapenems } \\
\hline Imipenem & n.a. & $44.7 \pm 3.2$ & $35.4,56.6(21.2)$ \\
\hline Ertapenem & 72.6 & $57.4 \pm 6.3$ & $43.3,82.5(39.2)$ \\
\hline \multicolumn{4}{|c|}{ Cephalosporins } \\
\hline Cefoxitin & 59.8 & $57.8 \pm 5.2$ & $41.9,70.1(28.2)$ \\
\hline Ceftazidime & 66.0 & $68.3 \pm 5.7$ & $52.8,88.1(35.3)$ \\
\hline \multicolumn{4}{|c|}{ Monocyclic beta-lactams } \\
\hline Aztreonam & 59.6 & $58.4 \pm 2.7$ & $48.3,69.3(21.0)$ \\
\hline BAL30072 & n.a. & $64.7 \pm 4.7$ & $50.2,81.4(31.2)$ \\
\hline \multicolumn{4}{|c|}{ Oxazolidinones } \\
\hline Linezolid & 47.6 & $43.4 \pm 4.0$ & $32.5,53.5(21.0)$ \\
\hline Sutezolid & n.a. & $44.0 \pm 3.9$ & $32.6,56.8(24.2)$ \\
\hline \multicolumn{4}{|c|}{ Penicillines } \\
\hline Aminopenicillanic acid & 39.9 & $38.1 \pm 0.7$ & $35.0,41.5(6.5)$ \\
\hline Piperacillin & 86.6 & $77.5 \pm 3.6$ & $56.1,90.0(33.9)$ \\
\hline \multicolumn{4}{|c|}{ Quinolones } \\
\hline Nalidixic acid & 34.3 & $36.5 \pm 1.4$ & $32.6,42.7(10.1)$ \\
\hline Fleroxacin & 46.6 & $46.1 \pm 1.9$ & $39.8,55.5(15.7)$ \\
\hline \multicolumn{4}{|c|}{ Tetracyclines } \\
\hline Minocycline & 66.2 & $67.5 \pm 1.4$ & $61.4,72.9(11.5)$ \\
\hline Tigecycline & 76.2 & $76.6 \pm 3.5$ & $65.5,86.7(21.2)$ \\
\hline \multicolumn{4}{|c|}{ Beta-lactamase inhibitors } \\
\hline Clavulanic acid & 38.6 & $37.5 \pm 1.1$ & $32.1,40.4(8.3)$ \\
\hline Tazobactam & 47.0 & $44.2 \pm 3.0$ & $39.3,52.5(13.2)$ \\
\hline
\end{tabular}

\section{Perspectives}

In the near future we plan to extend the amount of information present in the database. For instance, in order to guarantee reproducibility, we plan to make available the input and output files of our simulations. Furthermore, the database will be extended towards two main directions. From one side we will include more compounds, covering additional antimicrobial classes. At the same time, for each compound, we will setup parameters at different $\mathrm{pHs}$ including at least two more cases (low and high-pH) in addition 
to the physiological $\mathrm{pH}$ already considered. We plan to include in the individual page of each compound the relevant literature reporting on molecular properties from both experimental and computational studies. From the technical point of view we plan to improve the key parameters reported, in particular dihedral angles, by comparison with quantum-mechanical dynamics in presence of implicit and explicit solvent molecules, using biased molecular dynamics techniques [99-102]. Future refinements of the database will include the possibility to use a better water model to perform classical MD simulations. Finally, future directions include also performing MD simulations in solvents different than water (e.g., non polar solvents and "organic broths") in order to further improve conformational sampling while (possibly) mimicking interactions with functional groups in biomolecules such as proteins, nucleic acids, and membranes.

\section{Acknowledgments}

The research leading to these results was conducted as part of the Translocation consortium (www.translocation.eu) and has received support from the Innovative Medicines Initiatives Joint Undertaking under Grant Agreement n115525, resources which are composed of financial contribution from the European Union seventh framework programme (FP7/2007-2013) and EFPIA companies in kind contribution. The authors thank M. Kohler (European ScreeningPort, Hambourg - DE), I. Bodrenko (Department of Physics, University of Cagliari - IT) and M. A. Scorciapino (Department of Biomedical Sciences, University of Cagliari - IT) for usability tests and useful discussions about the database.

\section{Author Contributions}

G.M., A.V.V., P.R., M.C. designed research; G.M., A.V.V. performed research; G.M., A.V.V., G.S., A.B. analyzed the data and implemented the database. All authors wrote, read and approved the final manuscript.

\section{Conflicts of Interest}

The authors declare no conflict of interest.

\section{Appendix A}

Table A1. List of antimicrobial compounds included in the current version of the database.

\begin{tabular}{ccccc}
\hline Compound & $\begin{array}{c}\text { Molecular } \\
\text { Formula }\end{array}$ & $\begin{array}{c}\text { Number } \\
\text { of Atoms }\end{array}$ & $\begin{array}{c}\text { Molecular } \\
\text { Weight }\end{array}$ & $\begin{array}{c}\text { Physiological } \\
\text { Charge }\end{array}$ \\
\hline Carbapenems & & & \\
\hline
\end{tabular}


Table A1. Cont.

\begin{tabular}{ccccc}
\hline Molecular & $\begin{array}{c}\text { Number } \\
\text { Formula }\end{array}$ & $\begin{array}{c}\text { Molecular } \\
\text { of Atoms }\end{array}$ & $\begin{array}{c}\text { Physiological } \\
\text { Charge }\end{array}$ \\
\hline Carbapenems & & 339.4099 & 0 \\
\hline Biapenem & & & & 0 \\
\hline
\end{tabular}
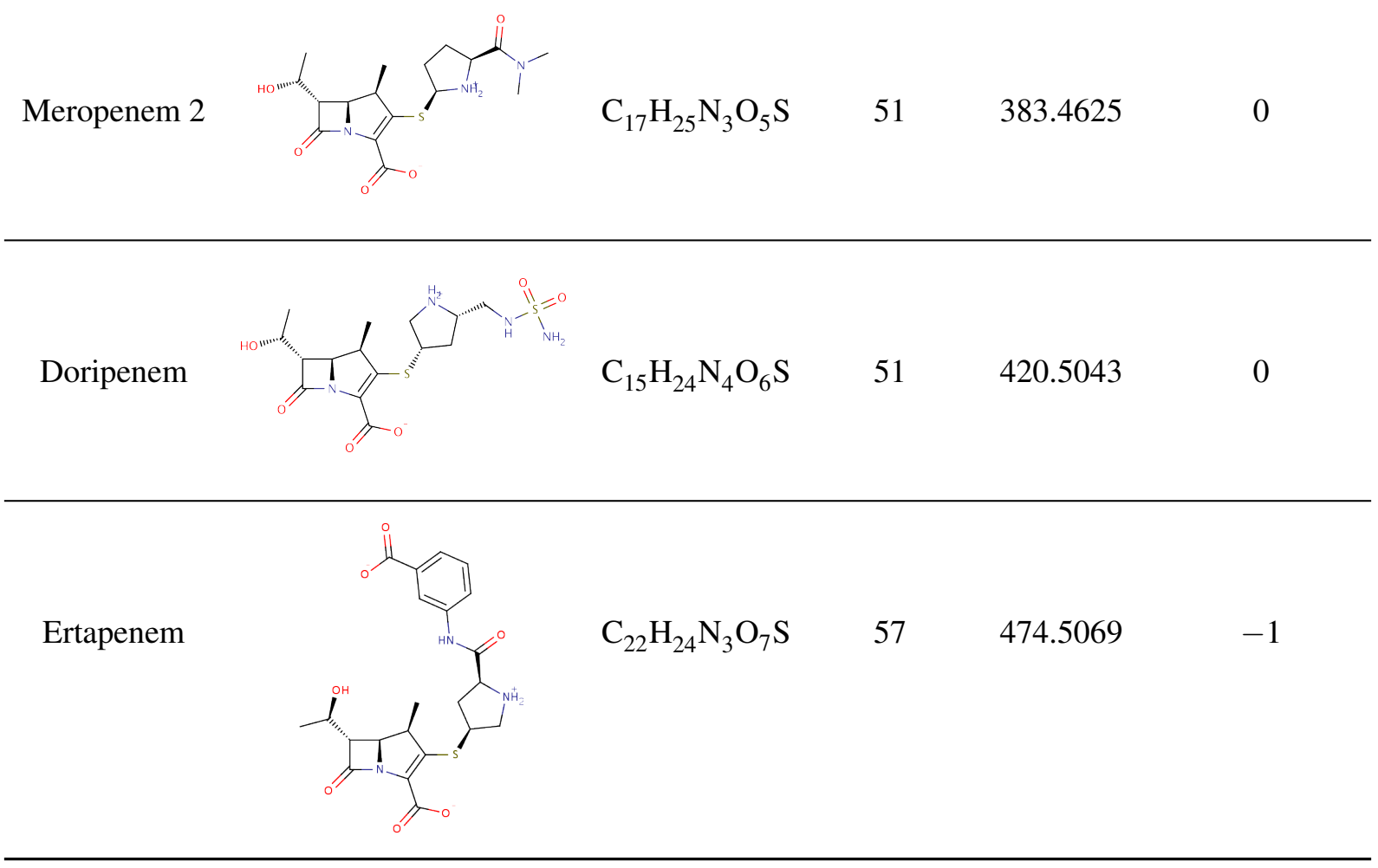
Table A1. Cont.

\begin{tabular}{|c|c|c|c|c|c|}
\hline & Compound & $\begin{array}{c}\text { Molecular } \\
\text { Formula }\end{array}$ & $\begin{array}{l}\text { Number } \\
\text { of Atoms }\end{array}$ & $\begin{array}{c}\text { Molecular } \\
\text { Weight }\end{array}$ & $\begin{array}{c}\text { Physiological } \\
\text { Charge }\end{array}$ \\
\hline \multicolumn{6}{|c|}{ Cephalosporins } \\
\hline Cefoxitin & & $\mathrm{C}_{16} \mathrm{H}_{16} \mathrm{~N}_{3} \mathrm{O}_{7} \mathrm{~S}_{2}$ & 44 & 426.4441 & -1 \\
\hline Cefotaxime & & $\mathrm{C}_{16} \mathrm{H}_{16} \mathrm{~N}_{5} \mathrm{O}_{7} \mathrm{~S}_{2}$ & 46 & 454.4575 & -1 \\
\hline Cefepime & & $\mathrm{C}_{19} \mathrm{H}_{24} \mathrm{~N}_{6} \mathrm{O}_{5} \mathrm{~S}_{2}$ & 56 & 480.5611 & 0 \\
\hline \multicolumn{5}{|l|}{ Cefpirome } & 0 \\
\hline Ceftobiprole & & $\mathrm{C}_{20} \mathrm{H}_{22} \mathrm{~N}_{8} \mathrm{O}_{6} \mathrm{~S}_{2}$ & 58 & 534.5687 & 0 \\
\hline Ceftazidime & & $\mathrm{C}_{22} \mathrm{H}_{21} \mathrm{~N}_{6} \mathrm{O}_{7} \mathrm{~S}_{2}$ & 58 & 545.5681 & -1 \\
\hline \multicolumn{6}{|c|}{ Monocyclic beta-lactams } \\
\hline Aztreonam & & $\mathrm{C}_{13} \mathrm{H}_{15} \mathrm{~N}_{5} \mathrm{O}_{8} \mathrm{~S}_{2}$ & 43 & 433.41690 & -2 \\
\hline
\end{tabular}


Table A1. Cont.

\begin{tabular}{|c|c|c|c|c|c|}
\hline & Compound & $\begin{array}{l}\text { Molecular } \\
\text { Formula }\end{array}$ & $\begin{array}{l}\text { Number } \\
\text { of Atoms }\end{array}$ & $\begin{array}{c}\text { Molecular } \\
\text { Weight }\end{array}$ & $\begin{array}{c}\text { Physiological } \\
\text { Charge }\end{array}$ \\
\hline \multicolumn{6}{|c|}{ Monocyclic beta-lactams } \\
\hline Tigemonam & & $\mathrm{C}_{12} \mathrm{H}_{13} \mathrm{~N}_{5} \mathrm{O}_{9} \mathrm{~S}_{2}$ & 41 & 435.3897 & -2 \\
\hline & & $\mathrm{C}_{12} \mathrm{H}_{12} \mathrm{~N}_{6} \mathrm{O}_{10} \mathrm{~S}_{2}$ & 42 & 464.3879 & -2 \\
\hline BAL19764 & & $\mathrm{C}_{14} \mathrm{H}_{13} \mathrm{~N}_{6} \mathrm{O}_{9} \mathrm{~S}_{2}$ & 44 & 473.4178 & -1 \\
\hline Nocardicin & & $\mathrm{C}_{23} \mathrm{H}_{22} \mathrm{~N}_{4} \mathrm{O}_{9}$ & 58 & 498.4422 & -2 \\
\hline BAL300072 & & $\mathrm{C}_{16} \mathrm{H}_{17} \mathrm{~N}_{6} \mathrm{O}_{10} \mathrm{~S}_{2}$ & 51 & 517.47038 & -1 \\
\hline \multicolumn{6}{|c|}{ Oxazolidinones } \\
\hline Linezolid & & $\mathrm{C}_{16} \mathrm{H}_{20} \mathrm{FN}_{3} \mathrm{O}_{4}$ & 44 & 337.3461 & 0 \\
\hline
\end{tabular}


Table A1. Cont.

\begin{tabular}{cccccc}
\hline Compound & $\begin{array}{c}\text { Molecular } \\
\text { Formula }\end{array}$ & $\begin{array}{c}\text { Number } \\
\text { of Atoms }\end{array}$ & $\begin{array}{c}\text { Molecular } \\
\text { Weight }\end{array}$ & $\begin{array}{c}\text { Physiological } \\
\text { Charge }\end{array}$ \\
\hline Oxazolidinones & & & & \\
\hline
\end{tabular}

Penicillines

Aminipenicillanic acid

Ticarcillin


Table A1. Cont.

\begin{tabular}{|c|c|c|c|c|}
\hline Compound & $\begin{array}{c}\text { Molecular } \\
\text { Formula }\end{array}$ & $\begin{array}{l}\text { Number } \\
\text { of Atoms }\end{array}$ & $\begin{array}{c}\text { Molecular } \\
\text { Weight }\end{array}$ & $\begin{array}{c}\text { Physiological } \\
\text { Charge }\end{array}$ \\
\hline \multicolumn{5}{|c|}{ Penicillines } \\
\hline Piperacillin & $\mathrm{C}_{23} \mathrm{H}_{26} \mathrm{~N}_{5} \mathrm{O}_{7} \mathrm{~S}$ & 62 & 516.5468 & -1 \\
\hline \multicolumn{5}{|c|}{ Quinolones } \\
\hline Nalidixic acid & $\mathrm{C}_{12} \mathrm{H}_{11} \mathrm{~N}_{2} \mathrm{O}_{3}$ & 28 & 231.2273 & -1 \\
\hline Norfloxacin & $\mathrm{C}_{16} \mathrm{H}_{18} \mathrm{FN}_{3} \mathrm{O}_{3}$ & 41 & 319.3308 & 0 \\
\hline Ciprofloxacin & $\mathrm{C}_{17} \mathrm{H}_{18} \mathrm{FN}_{3} \mathrm{~N}_{3} \mathrm{O}_{3}$ & 42 & 331.3415 & 0 \\
\hline Enrofloxacin & $\mathrm{C}_{19} \mathrm{H}_{21} \mathrm{FN}_{3} \mathrm{~N}_{3} \mathrm{O}_{3}$ & 47 & 358.3867 & -1 \\
\hline Levofloxacin & $\mathrm{C}_{18} \mathrm{H}_{19} \mathrm{FN}_{3} \mathrm{~N}_{3} \mathrm{O}_{4}$ & 45 & 360.3596 & -1 \\
\hline Fleroxacin & $\mathrm{C}_{17} \mathrm{H}_{17} \mathrm{~F}_{3} \mathrm{~N}_{3} \mathrm{O}_{3}$ & 43 & 368.3304 & -1 \\
\hline
\end{tabular}


Table A1. Cont.

\begin{tabular}{ccccc}
\hline Compound & $\begin{array}{c}\text { Molecular } \\
\text { Formula }\end{array}$ & $\begin{array}{c}\text { Number } \\
\text { of Atoms }\end{array}$ & $\begin{array}{c}\text { Molecular } \\
\text { Weight }\end{array}$ & $\begin{array}{c}\text { Physiological } \\
\text { Charge }\end{array}$ \\
\hline Tetracyclines & & & \\
\hline
\end{tabular}

Tigecycline

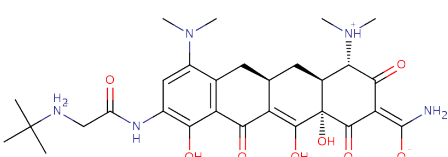

$\mathrm{C}_{29} \mathrm{H}_{40} \mathrm{~N}_{5} \mathrm{O}_{8}$

$82 \quad 586.6566$

1

Beta-lactamase inhibitors

Clavulanic acid

Sulbactam


Table A2. Root-mean-square displacement between the B3LYP/6-31G ${ }^{\star \star}$ optimized geometry and the minimum-energy structure obtained with the GAFF parameters of the database.

\begin{tabular}{|c|c|c|}
\hline Class & Compound & $\operatorname{RMSD}(\AA)$ \\
\hline \multirow{7}{*}{ Carbapenems } & Imipenem & 1.59 \\
\hline & Panipenem & 1.70 \\
\hline & Biapenem & 1.69 \\
\hline & Meropenem & 1.66 \\
\hline & Meropenem-2 & 1.65 \\
\hline & Doripenem & 1.66 \\
\hline & Ertapenem & 1.71 \\
\hline \multirow{5}{*}{ Cephalosporins } & Cefoxitin & 1.63 \\
\hline & Cefotaxime & 1.63 \\
\hline & Cefepime & 1.62 \\
\hline & Ceftobiprole & 1.64 \\
\hline & Ceftazidime & 1.60 \\
\hline \multirow{6}{*}{ Monocyclic beta-lactams } & Aztreonam & 1.60 \\
\hline & Tigemonam & 1.69 \\
\hline & Carumonam & 1.64 \\
\hline & BAL19764 & 1.65 \\
\hline & Nocardicin & 1.66 \\
\hline & BAL30072 & 1.76 \\
\hline \multirow{2}{*}{ Oxazolidinones } & Linezolid & 1.68 \\
\hline & Sutezolid & 1.67 \\
\hline \multirow{7}{*}{ Penicillines } & Aminopenicillanic Acid & 1.73 \\
\hline & Benzylpenicillin & 1.64 \\
\hline & Ampicillin & 1.65 \\
\hline & Carbenicillin & 1.68 \\
\hline & Ticarcillin & 1.68 \\
\hline & Oxacillin & 1.64 \\
\hline & Piperacillin & 1.74 \\
\hline \multirow{6}{*}{ Quinolones } & Nalidixic Acid & 1.62 \\
\hline & Norfloxacin & 1.58 \\
\hline & Ciprofloxacin & 1.58 \\
\hline & Enrofloxacin & 1.58 \\
\hline & Levofloxacin & 1.56 \\
\hline & Fleroxacin & 1.59 \\
\hline \multirow{2}{*}{ Tetracyclines } & Minocycline & 1.62 \\
\hline & Tigecycline & 1.65 \\
\hline \multirow{4}{*}{ Beta-lactamase inhibitors } & Clavulanic Acid & 1.66 \\
\hline & Sulbactam & 1.63 \\
\hline & Avibactam & 1.62 \\
\hline & Tazobactam & 1.66 \\
\hline
\end{tabular}




\section{References}

1. Csermely, P.; Palotai, R.; Nussinov, R. Induced fit, conformational selection and independent dynamic segments: An extended view of binding events. Trends Biochem. Sci. 2010, 35, 539-546.

2. Baron, R.; McCammon, J.A. Molecular Recognition and Ligand Association. Ann. Rev. Phys. Chem. 2013, 64, 151-175.

3. Jorgensen, W. The many roles of computation in drug discovery. Science 2004, 303, 1813-1818.

4. Gilson, M.K.; Zhou, H.X. Calculation of Protein-Ligand Binding Affinities. Ann. Rev. Biophys. Biomol. Struct. 2007, 36, 21-42.

5. Baron, R.; McCammon, J.A. Molecular Recognition and Ligand Association. Ann. Rev. Phys. Chem. 2013, 64, 151-175.

6. Vargiu, A.V.; Magistrato, A. Atomistic-Level Portrayal of Drug-DNA Interplay: A History of Courtships and Meetings Revealed by Molecular Simulations. ChemMedChem 2014, 9, 1966-1981.

7. Boehr, D.D.; Nussinov, R.; Wright, P.E. The role of dynamic conformational ensembles in biomolecular recognition. Nat. Chem. Biol. 2009, 5, 789-796.

8. Van Gunsteren, W.F.; Bakowies, D.; Baron, R.; Chandrasekhar, I.; Christen, M.; Daura, X.; Gee, P.; Geerke, D.P.; Glaettli, A.; Huenenberger, P.H.; et al. Biomolecular modeling: Goals, problems, perspectives. Angew. Chem. Int. Ed. 2006, 45, 4064-4092.

9. Sherwood, P.; Brooks, B.R.; Sansom, M.S.P. Multiscale methods for macromolecular simulations. Curr. Opin. Struc. Biol. 2008, 18, 630-640.

10. Cheatham, T.E., III; Case, D.A. Twenty-Five Years of Nucleic Acid Simulations. Biopolymers 2013, 99, 969-977.

11. Lee, E.H.; Hsin, J.; Sotomayor, M.; Comellas, G.; Schulten, K. Discovery through the Computational Microscope. Structure 2009, 17, 1295-1306.

12. Amodeo, G.F.; Scorciapino, M.A.; Messina, A.; De Pinto, V.; Ceccarelli, M. Charged residues distribution modulates selectivity of the open state of human isoforms of the voltage dependent anion-selective channel. PLOS ONE 2014, 9, e103879.

13. Dodson, G.G.; Lane, D.P.; Verma, C.S. Molecular simulations of protein dynamics: New windows on mechanisms in biology. EMBO Rep. 2008, 9, 144-150.

14. Dror, R.O.; Dirks, R.M.; Grossman, J.P.; Xu, H.; Shaw, D.E. Biomolecular Simulation: A Computational Microscope for Molecular Biology. Ann. Rev. Biophys. 2012, 41, 429-452.

15. Karplus, M.; Lavery, R. Significance of Molecular Dynamics Simulations for Life Sciences. Isr. J. Chem. 2014, 54, 1042-1051.

16. Mortier, J.; Rakers, C.; Bermudez, M.; Murgueitio, M.S.; Riniker, S.; Wolber, G. The impact of molecular dynamics on drug design: Applications for the characterization of ligand-macromolecule complexes. Drug Discov. Today 2015, 20, 686-702.

17. Schlick, T. Molecular Modeling and Simulation: An Interdisciplinary Guide; Interdisciplinary applied mathematics, Springer: New York, NY, USA, 2010. 
18. Gelin, B.R. Testing and comparison of empirical force fields: Techniques and problems. In Computer Simulation of Biomolecular Systems: Theoretical and Experimental Applications; Gunsteren, W.F.V., Weiner, P., Wilkinson, A.J., Eds.; ESCOM: Leiden, The Netherlands, 1993; Volume 2, pp. 127-146.

19. Cornell, W.D.; Cieplak, P.; Bayly, C.I.; Gould, I.R.G.; Merz, K.M.J.; Ferguson, D.M.; Spellmeyer, D.C.; Fox, T.; Caldwell, J.W.; Kollman, P.A. A Second Generation Force Field for the Simulation of Proteins, Nucleic Acids, and Organic Molecules. J. Am. Chem. Soc. 1995, 117, 5179-5197.

20. Ceccarelli, M.; Lutz, M.; Marchi, M. A density functional normal mode calculation of a bacteriochlorophyll a derivative. J. Am. Chem. Soc. 2000, 122, 3532-3533.

21. Ceccarelli, M.; Marchi, M. Simulation and Modeling of the Rhodobacter sphaeroides Bacterial Reaction Center II: Primary Charge Separation. J. Phys. Chem. B 2003, 107, 5630-5641.

22. Piana, S.; Klepeis, J.L.; Shaw, D.E. Assessing the accuracy of physical models used in protein-folding simulations: Quantitative evidence from long molecular dynamics simulations. Curr. Opin. Struct. Biol. 2014, 24, 98-105.

23. Šponer, J.; Banáš, P.; Jurečka, P.; Zgarbová, M.; Kührová, P.; Havrila, M.; Krepl, M.; Stadlbauer, P.; Otyepka, M. Molecular Dynamics Simulations of Nucleic Acids. From Tetranucleotides to the Ribosome. J. Phys. Chem. Lett. 2014, 5, 1771-1782.

24. Schmidt, T.H.; Kandt, C. LAMBADA and InflateGRO2: Efficient Membrane Alignment and Insertion of Membrane Proteins for Molecular Dynamics Simulations. J. Chem. Inf. Mod. 2012, $52,2657-2669$.

25. Lindorff-Larsen, K.; Piana, S.; Palmo, K.; Maragakis, P.; Klepeis, J.L.; Dror, R.O.; Shaw, D.E. Improved side-chain torsion potentials for the Amber ff99SB protein force field. Proteins 2010, 78, 1950-1958.

26. Graen, T.; Hoefling, M.; Grubmueller, H. AMBER-DYES: Characterization of Charge Fluctuations and Force Field Parameterization of Fluorescent Dyes for Molecular Dynamics Simulations. J. Chem. Theory Comput. 2014, 10, 5505-5512.

27. Dupradeau, F.Y.; Cézard, C.; Lelong, R.; Stanislawiak, E.; Pêcher, J.; Delepine, J.C.; Cieplak, P. R.E.DD.B.: A database for RESP and ESP atomic charges, and force field libraries. Nucleic Acids Res. 2008, 36, D360-D367.

28. Dupradeau, F.Y.; Pigache, A.; Zaffran, T.; Savineau, C.; Lelong, R.; Grivel, N.; Lelong, D.; Rosanski, W.; Cieplak, P. The R.E.D. tools: Advances in RESP and ESP charge derivation and force field library building. Phys. Chem. Chem. Phys. 2010, 12, 7821-7839.

29. AMBER Parameter Database. Available online: http://www.pharmacy.manchester.ac.uk/bryce/ amber/ (accessed on 20 July 2014).

30. Marvin 14.8.25.0. ChemAxon 2014. Available online: http://www.chemaxon.com (accessed on 30 November 2014).

31. Case, D.; Babin, V.; Berryman, J.; Betz, R.; Cai, Q.; Cerutti, D.; Cheatham, T., III; Darden, T.; Duke, R.; Gohlke, H.; et al. Amber 14. University of California: San Francisco, CA, USA, 2014. 
32. Frisch, M.J.; Trucks, G.W.; Schlegel, H.B.; Scuseria, G.E.; Robb, M.A.; Cheeseman, J.R.; Scalmani, G.; Barone, V.; Mennucci, B.; Petersson, G.A.; et al. Gaussian09 Revision A.02; Gaussian Inc.: Wallingford, CT, USA, 2009.

33. Stavenger, R.A.; Winterhalter, M. TRANSLOCATION Project: How to Get Good Drugs into Bad Bugs. Sci. Transl. Med. 2014, 6, 228ed7.

34. Nikaido, H. Prevention of drug access to bacterial targets: Permeability barriers and active efflux. Science 1994, 264, 382-388.

35. Ceccarelli, M.; Ruggerone, P. Physical insights into permeation of and resistance to antibiotics in bacteria. Curr. Drug Targ. 2008, 9, 779-788.

36. Wang, J.; Wolf, R.M.; Caldwell, J.W.; Kollman, P.A.; Case, D.A. Development and testing of a general amber force field. J. Comput. Chem. 2004, 25, 1157-1174.

37. Bolton, E.E.; Wangand, Y.; Thiessenand, P.A.; Bryant, S.H. PubChem: Integrated Platform of Small Molecules and Biological Activities. Annu. Rep. Comput. Chem. 2008, 4, 217-241.

38. Kohn, W. Nobel Lecture: Electronic structure of matter-wave functions and density functionals. Rev. Mod. Phys. 1999, 71, 1253-1266.

39. Becke, A.D. Density-functional thermochemistry. III. The role of exact exchange. J. Chem. Phys. 1993, 98, 5648-5652.

40. Kim, K.; Jordan, K.D. Comparison of Density Functional and MP2 Calculations on the Water Monomer and Dimer. J. Phys. Chem. 1994, 98, 10089-10094.

41. Pople, J.A. Quantum Chemical Models (Nobel Lecture). Angew. Chem. Int. Ed. 1999, 38, 1894-1902.

42. Malloci, G.; Joblin, C.; Mulas, G. On-line database of the spectral properties of polycyclic aromatic hydrocarbons. Chem. Phys. 2007, 332, 353-359.

43. Malloci, G.; Cappellini, G.; Mulas, G.; Mattoni, A. Electronic and optical properties of families of polycyclic aromatic hydrocarbons: A systematic (time-dependent) density functional theory study. Chem. Phys. 2011, 384, 19-27.

44. Tomasi, J.; Mennucci, B.; Cammi, R. Quantum Mechanical Continuum Solvation Models. Chem. Rev. 2005, 105, 2999-3094.

45. O’Boyle, N.M.; Tenderholt, A.L.; Langner, K.M. cclib: A library for package-independent computational chemistry algorithms. J. Comput. Chem. 2008, 29, 839-845.

46. Allouche, A.R. Gabedit-A graphical user interface for computational chemistry softwares. J. Comput. Chem. 2011, 32, 174-182.

47. Singh, U.C.; Kollman, P.A. An approach to computing electrostatic charges for molecules. J. Comput. Chem. 1984, 5, 129-145.

48. Breneman, C.M.; Wiberg, K.B. Determining atom-centered monopoles from molecular electrostatic potentials. The need for high sampling density in formamide conformational analysis. J. Comput. Chem. 1990, 11, 361-373.

49. Bayly, C.I.; Cieplak, P.; Cornell, W.; Kollman, P.A. A well-behaved electrostatic potential based method using charge restraints for deriving atomic charges: The RESP model. J. Phys. Chem. 1993, 97, 10269-10280. 
50. Wang, J.; Wang, W.; Kollman, P.A.; Case, D.A. Automatic atom type and bond type perception in molecular mechanical calculations. J. Mol. Graph. Model. 2006, 25, 247-260.

51. Cheng, T.; Zhao, Y.; Li, X.; Lin, F.; Xu, Y.; Zhang, X.; Li, Y.; Wang, R.; Lai, L. Computation of Octanol-Water Partition Coefficients by Guiding an Additive Model with Knowledge. J. Chem. Inf. Model. 2007, 47, 2140-2148.

52. Pyrkov, T.V.; Chugunov, A.O.; Krylov, N.A.; Nolde, D.E.; Efremov, R.G. PLATINUM: A web tool for analysis of hydrophobic/hydrophilic organization of biomolecular complexes. Bioinformatics 2009, 25, 1201-1202.

53. Jorgensen, W.L.; Chandrasekhar, J.; Madura, J.D.; Impey, R.W.; Klein, M.L. Comparison of simple potential functions for simulating liquid water. J. Chem. Phys. 1983, 79, 926-935.

54. Joung, I.S.; Cheatham, T.E. Determination of Alkali and Halide Monovalent Ion Parameters for Use in Explicitly Solvated Biomolecular Simulations. J. Phys. Chem. B 2008, 112, 9020-9041.

55. Berendsen, H.J.C.; Postma, J.P.M.; van Gunsteren, W.F.; DiNola, A.; Haak, J.R. Molecular dynamics with coupling to an external bath. J. Chem. Phys. 1984, 81, 3684-3690.

56. Loncharich, R.J.; Brooks, B.R.; Pastor, R.W. Langevin dynamics of peptides: The frictional dependence of isomerization rates of $\mathrm{N}$-acetylalanyl- $\mathrm{N}^{\prime}$-methylamide. Biopolymers 1992, 32, 523-535.

57. Roe, D.R.; Cheatham, T.E. PTRAJ and CPPTRAJ: Software for Processing and Analysis of Molecular Dynamics Trajectory Data. J. Chem. Theory Comput. 2013, 9, 3084-3095.

58. Nag, A.; Chakraborty, D.; Chandra, A. Effects of ion concentration on the hydrogen bonded structure of water in the vicinity of ions in aqueous $\mathrm{NaCl}$ solutions. J. Chem. Sci. 2008, 120, 71-77.

59. Luzar, A.; Chandler, D. Effect of Environment on Hydrogen Bond Dynamics in Liquid Water. Phys. Rev. Lett. 1996, 76, 928-931.

60. Luzar, A.; Chandler, D. Hydrogen-bond kinetics in liquid Water. Nature 1996, 379, 55-57.

61. Sutmann, G.; Vallauri, R. Hydrogen bonded clusters in the liquid phase: I. Analysis of the velocity correlation function of water triplets. J. Phys. Condens. Matter 1998, 10, 9231-9240.

62. Chandra, A. Effects of Ion Atmosphere on Hydrogen-Bond Dynamics in Aqueous Electrolyte Solutions. Phys. Rev. Lett. 2000, 85, 768-771.

63. Shao, J.; Tanner, S.W.; Thompson, N.; Cheatham, T.E. Clustering Molecular Dynamics Trajectories: 1. Characterizing the Performance of Different Clustering Algorithms. J. Chem. Theory Comput. 2007, 3, 2312-2334.

64. van der Spoel, D.; van Buuren, A.R.; Apol, E.; Meulenhoff, P.J.; Tieleman, D.P.; Sijbers, A.L.T.M.; Hess, B.; Feenstra, K.A.; Lindahl, E.; van Drunen, R.; Berendsen, H.J.C. Gromacs User Manual version 3.0. Nijenborgh 4, 9747 AG Groningen, The Netherlands. 2001. Available online: http://www.gromacs.org (accessed on 29 June 2014).

65. Bonomi, M.; Branduardi, D.; Bussi, G.; Camilloni, C.; Provasi, D.; Raiteri, P.; Donadio, D.; Marinelli, F.; Pietrucci, F.; Broglia, R.A.; Parrinello, M. PLUMED: A portable plugin for free-energy calculations with molecular dynamics. Comput. Phys. Comm. 2009, 180, 1961-1972.

66. Theodorou, D.N.; Suter, U.W. Shape of unperturbed linear polymers: Polypropylene. Macromolecules 1985, 18, 1206-1214. 
67. O’Boyle, N.; Banck, M.; James, C.; Morley, C.; Vandermeersch, T.; Hutchison, G. Open Babel: An open chemical toolbox. J. Cheminf. 2011, 3, doi:10.1186/1758-2946-3-33.

68. The PyMOL Molecular Graphics System, Version 1.3r1. The PyMOL Molecular Graphics System, Version 1.3, Schrödinger, LLC, Mannheim, Germany.

69. Humphrey, W.; Dalke, A.; Schulten, K. VMD_Visual Molecular Dynamics. J. Mol. Graph. 1996, 14, 33-38.

70. Kumar, A.; Hajjar, E.; Ruggerone, P.; Ceccarelli, M. Molecular simulations reveal the mechanism and the determinants for ampicillin translocation through OmpF. J. Phys. Chem. B 2010, 114, 9608-9616.

71. Hajjar, E.; Bessonov, A.; Molitor, A.; Kumar, A.; Mahendran, K.R.; Winterhalter, M.; Pagès, J.M.; Ruggerone, P.; Ceccarelli, M. Toward screening for antibiotics with enhanced permeation properties through bacterial porins. Biochemistry 2010, 49, 6928-6935.

72. Lou, H.; Chen, M.; Black, S.S.; Bushell, S.R.; Ceccarelli, M.; Mach, T.; Beis, K.; Low, A.S.; Bamford, V.A.; Booth, I.R.; Bayley, H.; Naismith, J.H. Altered Antibiotic Transport in OmpC Mutants Isolated from a Series of Clinical Strains of Multi-Drug Resistant E. coli. PLoS ONE 2011, 6, e25825.

73. Collu, F.; Vargiu, A.V.; Dreier, J.; Cascella, M.; Ruggerone, P. Recognition of Imipenem and Meropenem by the RND-Transporter MexB Studied by Computer Simulations. J. Am. Chem. Soc. 2012, 134, 19146-19158.

74. Vargiu, A.V.; Nikaido, H. Multidrug binding properties of the AcrB efflux pump characterized by molecular dynamics simulations. Proc. Natl. Acad. Sci. USA 2012, 109, 20637-20642.

75. Vargiu, A.V.; Ruggerone, P.; Opperman, T.J.; Nguyen, S.T.; Nikaido, H. Molecular Mechanism of MBX2319 Inhibition of Escherichia coli AcrB Multidrug Efflux Pump and Comparison with Other Inhibitors. Antimicrob. Agents Chemother. 2014, 58, 6224-6234.

76. JSmol: An Open-Source HTML5 Viewer for Chemical Structures in 3D. Available online: http://wiki.jmol.org/index.php/JSmol\#JSmol (accessed on 27 March 2015).

77. Ruiz-Carmona, S.; Alvarez-Garcia, D.; Foloppe, N.; Garmendia-Doval, A.B.; Juhos, S.; Schmidtke, P.; Barril, X.; Hubbard, R.E.; Morley, S.D. rDock: A Fast, Versatile and Open Source Program for Docking Ligands to Proteins and Nucleic Acids. PLoS Comput. Biol. 2014, 10, e1003571.

78. Trott, O.; Olson, A.J. AutoDock Vina: Improving the speed and accuracy of docking with a new scoring function, efficient optimization, and multithreading. J. Comput. Chem. 2010, 31, 455-461.

79. Zacharias, M. Protein-protein docking with a reduced protein model accounting for side-chain flexibility. Protein Sci. 2003, 12, 1271-1282.

80. Zacharias, M. Accounting for conformational changes during protein-protein docking. Curr. Opin. Struct. Biol. 2010, 20, 180-186.

81. Bonvin, A. Flexible protein-protein docking. Curr. Opin. Struct. Biol. 2006, 16, 194-200.

82. Totrov, M.; Abagyan, R. Flexible ligand docking to multiple receptor conformations: A practical alternative. Curr. Opin. Struct. Biol. 2008, 18, 178-184. 
83. Andrusier, N.; Mashiach, E.; Nussinov, R.; Wolfson, H.J. Principles of flexible protein-protein docking. Proteins 2008, 73, 271-289.

84. B-Rao, C.; Subramanian, J.; Sharma, S.D. Managing protein flexibility in docking and its applications. Drug Discov. Today 2009, 14, 394-400.

85. Yuriev, E.; Agostino, M.; Ramsland, P.A. Challenges and advances in computational docking: 2009 in review. J. Mol. Recognit. 2011, 24, 149-164.

86. Sinko, W.; Lindert, S.; McCammon, J.A. Accounting for Receptor Flexibility and Enhanced Sampling Methods in Computer-Aided Drug Design. Chem. Biol. Drug Des. 2013, 81, 41-49.

87. Cavasotto, C.N.; Orry, A.J.W. Ligand docking and structure-based virtual screening in drug discovery. Curr. Opin. Struct. Biol. 2007, 7, 1006-1014.

88. Amaro, R.E.; Baron, R.; McCammon, J.A. An improved relaxed complex scheme for receptor flexibility in computer-aided drug design. J. Comput. -Aided Mol. Des. 2008, 22, 693-705.

89. Vargiu, A.V.; Collu, F.; Schulz, R.; Pos, K.M.; Zacharias, M.; Kleinekathöfer, U.; Ruggerone, P. Effect of the F610A Mutation on Substrate Extrusion in the AcrB Transporter: Explanation and Rationale by Molecular Dynamics Simulations. J. Am. Chem. Soc. 2011, 133, 10704-10707.

90. Asthana, S.; Shukla, S.; Ruggerone, P.; Vargiu, A.V. Molecular Mechanism of Viral Resistance to a Potent Non-nucleoside Inhibitor Unveiled by Molecular Simulations. Biochemistry 2014, 53, 6941-6953.

91. Cha, H.J.; Müller, R.T.; Pos, K.M. Switch-Loop Flexibility Affects Transport of Large Drugs by the Promiscuous AcrB Multidrug Efflux Transporter. Antimicrob. Agents Chemother. 2014, 58, 4767-4772.

92. Ruggerone, P.; Murakami, S.; Pos, K.M.; Vargiu, A.V. RND efflux pumps: Structural information translated into function and inhibition mechanisms. Curr. Top. Med. Chem. 2013, 13, 3079-3100.

93. Li, X.Z.; Nikaido, H. Efflux-Mediated Drug Resistance in Bacteria An Update. Drugs 2009, 69, $1555-1623$.

94. Blair, J.; Richmond, G.; Piddock, L. Multidrug efflux pumps in Gram-negative bacteria and their role in antibiotic resistance. Future Microbiol. 2014, 9, 1165-1177.

95. Lomovskaya, O.; Zgurskaya, H.I.; Totrov, M.; Watkins, W.J. Waltzing transporters and 'the dance macabre' between humans and bacteria. Nat. Rev. Drug Discov. 2007, 6, 56-65.

96. Poole, K. Efflux-mediated antimicrobial resistance. J. Antimicrob. Chemother 2005, 56, 20-51.

97. Nikaido, H.; Pagés, J.M. Broad-specificity efflux pumps and their role in multidrug resistance of Gram-negative bacteria. FEMS Microbiol. Rev. 2012, 36, 340-363.

98. Chemicalize. ChemAxon 2014. Available online: http://www.chemicalize.org (accessed on 29 January 2014).

99. Hamelberg, D.; Mongan, J.; McCammon, J.A. Accelerated molecular dynamics: A promising and efficient simulation method for biomolecules. J. Chem. Phys. 2004, 120, 11919-11929.

100. Sugita, Y.; Okamoto, Y. Replica-exchange molecular dynamics method for protein folding. Chem. Phys. Lett. 1999, 314, 141-151.

101. Fukunishi, H.; Watanabe, O.; Takada, S. On the Hamiltonian replica exchange method for efficient sampling of biomolecular systems: Application to protein structure prediction. J. Chem. Phys. 2002, 116, 9058-9067. 
102. Laio, A.; Parrinello, M. Escaping free-energy minima. Proc. Natl. Acad. Sci. USA 2002,99, 12562-12566.

Sample Availability: Samples of the compounds are not available from the authors.

(c) 2015 by the authors; licensee MDPI, Basel, Switzerland. This article is an open access article distributed under the terms and conditions of the Creative Commons Attribution license (http://creativecommons.org/licenses/by/4.0/). 